\title{
Selected tumor markers in the routine diagnosis of chromophobe renal cell carcinoma
}

\author{
Anna M. Badowska-Kozakiewicz ${ }^{1}$, Michał P. Budzik², Paweł Koczkodaj ${ }^{1}$, Jacek Przybylski ${ }^{1}$
}

\author{
${ }^{1}$ Department of Human Biophysics and Physiology, Medical University of Warsaw, \\ Warsaw, Poland \\ ${ }^{2}$ Student Scientific Group of Cancer Cell Biology, Department of Human Biophysics \\ and Physiology, Medical University of Warsaw, Warsaw, Poland
}

Submitted: 23 September 2014

Accepted: 15 December 2014

Arch Med Sci 2016; 12, 4: 856-863

DOI: 10.5114/aoms.2015.51188

Copyright @ 2016 Termedia \& Banach

\author{
Corresponding author: \\ Anna M. Badowska-Kozakiewicz \\ Department of Human \\ Biophysics and Physiology \\ Medical University of Warsaw \\ 61 Zwirki i Wigury St \\ 02-091 Warsaw, Poland \\ Phone/fax: +48226287846 \\ E-mail: \\ abadowska@wum.edu.pl
}

\begin{abstract}
Renal cell carcinoma is one of the most malignant tumors, affecting men more frequently than women and constituting nearly $90 \%$ of all kidney tumors. Chromophobe renal cell carcinoma has been described as a new histological type of renal cell carcinoma. Chromophobe renal cell carcinoma constitutes up to $5 \%$ of all cases of kidney cancer. It is characterized by a significant number of deletions in many chromosomes, as well as the loss of entire chromosomes. Chromophobe renal cell carcinoma arises from tubular cells or cells of the macula densa. In contrast to other types of kidney cancer, it occurs with equal frequency in men and women, mostly in the sixth decade of life. It is characterized by a relatively good prognosis and exhibits a low degree of malignancy. Histopathologic diagnosis of ChRCC can be a diagnostic challenge because these tumors may resemble oncocytoma or conventional cancer. Research by Mathers et al. proposed the use of cytokeratin 7 as a marker useful in the differentiation of these changes.
\end{abstract}

Key words: chromophobe renal cell carcinoma, tumor markers, CD117, KAl1 protein.

\section{Introduction}

Renal cell carcinoma is one of the most malignant tumors, affecting men more frequently than women and constituting nearly $90 \%$ of all kidney tumors [1]. The incidence of kidney cancer varies geographically: the highest level is recorded in Europe, North America and Australia, the lowest in Africa, India, China and Japan. Currently, a reliable causative agent of renal cell carcinoma is unknown, although increasing evidence points to chromosomal defects contributing to its development. A growing number of cases of the disease at a young age and following cytostatic and immunosuppressive therapy has been described recently. The risk of kidney cancer also increases with smoking, obesity, hypertension and exposure to chemical agents, especially nitrosamines, cadmium and arsenic [2, 3]. The most common kidney cancer is clear cell carcinoma, also called conventional cancer. It accounts for approximately $80 \%$ of all cases of kidney cancer. This tumor derives from the epithelial tissue of proximal renal tubular sections [4] and histologically is composed of a clear, granular, eosinophilic cytoplasm [5]. Papillary renal cell carcinoma, also known as chromophil carcinoma, is a much less recognized re- 
nal cancer, occurring in about $10-15 \%$ of cases. Approximately $5 \%$ of cases of kidney cancer are chromophobe renal cell carcinoma (ChRCC), which owes its name to darker-colored cells. The least common types of kidney cancer, making up 1-2\%, include collecting duct cell carcinoma and sarcomatoid cell carcinoma [2].

\section{Epidemiology of chromophobe renal cell carcinoma}

Chromophobe renal cell carcinoma was described as a new histological type of renal cell carcinoma in 1985 by Thoenes et al. [6]. It owes its name to the inability of staining with conventional dyes, such as hematoxylin and eosin, and due to a high content of proteoglycans in the cytoplasm, strongly stained with Hale's colloidal iron [7]. Chromophobe renal cell carcinoma constitutes up to $5 \%$ of all cases of kidney cancer. It is characterized by a significant number of deletions in many chromosomes $(1,2,6,10,13,17,21, \mathrm{Y})$, as well as the loss of entire chromosomes [8]. Chromophobe renal cell carcinoma arises from tubular cells or cells of the macula densa. In contrast to other types of kidney cancer, it occurs with equal frequency in men and women, mostly in the sixth decade of life. It is characterized by a relatively good prognosis and exhibits a low degree of malignancy. Studies have shown a 5-year survival rate of $78-100 \%$, and a 10 -year survival rate in the range of $80-90 \%$ [9]. The growth of a tumor mass into the renal vein occurs in about $5 \%$ of cases, and the occurrence of metastases is observed in $6-7 \%$ of pathological lesions described as ChRCC $[10,11]$.

\section{Microscopic view of chromophobe renal cell carcinoma}

Microscopically, ChRCC can be observed in the form of solid or trabecular cell clusters with light, flocculent cytoplasm. Characteristic features of the cells include particularly pronounced cell membranes and irregular nuclear shapes with distinct nucleoli. The histopathological differential diagnosis of ChRCC should be based on differentiation from clear cell carcinoma and oncocytoma. Oncocytoma can develop in various organs. It is a mild form of a well-differentiated renal tumor, accounting for about $3-7 \%$ of kidney tumors. Histologically, this lesion is constructed of solid layers of large, polygonal and eosinophilic cells. Most of these cells are completely filled with a granular cytoplasm mainly composed of mitochondria [12].

Immunohistochemistry plays a valuable role in diagnosis of ChRCC. Chromophobe renal cell carcinoma cells have a positive reaction to Hale's colloidal iron and keratin, but negative immunostaining for vimentin, while the most common type of kidney cancer, clear cell carcinoma, displays co-expression of keratin and vimentin. Another feature differentiating ChRCC from oncocytoma is the presence of numerous cytoplasmic vesicles derived from the endoplasmic reticulum with a smooth surface and a diameter of $250-400 \mathrm{~nm}$ $[13,14]$.

\section{Macroscopic evaluation of chromophobe renal cell carcinoma}

The average size of a ChRCC tumor is $6.0 \mathrm{~cm}$, which is larger than other subtypes of kidney cancer. Its most common colors are beige, yellow and various shades of brown [15]. Chromophobe renal cell carcinoma is sometimes surrounded by necrotic lesions. A central scar on the tumor mass has also been described, but the frequency of its occurrence is unknown [16].

\section{Chromophobe renal cell carcinoma clinical presentation}

Chromophobe renal cell carcinoma is known to be the malignant counterpart to oncocytoma. It is generally recognized as a clinically low-stage, low-grade tumor [17]. Clinically, ChRCC is detected based on signs and symptoms, as with other types of kidney cancer. They include pain, hematuria, hypertension, polycythemia, hypercalcemia of unknown origin, fever and weight loss. Kidney cancer has been increasingly diagnosed at an earlier stage of development, mainly due to routine ultrasound examination. The classic triad of flank pain, hematuria, and palpable mass in the lumbar region is uncommon and is indicative of advanced disease [18].

\section{Treatment of chromophobe renal cell carcinoma}

Nephrectomy is the best way to treat ChRCC. In the past, radical nephrectomy was the standard surgical procedure. It consists of removal of the kidney along with perirenal fat, renal fascia, adrenal gland, ureter and regional lymph nodes. Partial nephrectomy is also performed in cases where preservation of the affected kidney is required. It consists of the removal of only pathological lesions along with the surrounding tissues. Nowadays, with advanced diagnostic techniques available, more ChRCC cases are recognized at an early stage of development. As a result, partial nephrectomy is performed more commonly [19].

Huang et al. retrospectively analyzed 2,991 patients with renal cell carcinoma who had undergone nephrectomy at the age of over 65 years. They showed that there were more cases of cardiovascular and chronic kidney disease in the group of patients who had undergone radical ne- 
phrectomy. The mortality rate in this group was also significantly higher than in a group of patients following partial nephrectomy [20].

Another analysis of a group of 648 patients treated surgically for renal cell carcinoma carried out by Thompson et al. also showed a correlation between radical nephrectomy and significantly increased mortality [21].

\section{Histological evaluation of chromophobe renal cell carcinoma}

The Fuhrman grade, which is one of the most important prognostic factors in the course of kidney cancer, plays an important role in its diagnosis. The classification of ChRCC is based on evaluation of changes in cell nuclei on a 4-point grade after staining with hematoxylin and eosin (H\&E). In this evaluation the following cell morphological features are taken: size of the cell nucleus, regularity of the nuclear outlines, and presence of nucleoli.

In stage 1 of histological malignancy of ChRCC cells, nuclei with morphology similar to nuclei of healthy kidney cells are detectable. This feature is thought to be associated with the best prognosis. ChRCC cells in stage 4 of histological malignancy have nuclei with numerous morphological changes; therefore, in these cases, prognosis is worse $[22,23]$. Particular consideration should be paid to the limited usefulness of the Fuhrman grade in estimating the prognosis of ChRCC. Nowadays, this classification is limited only to clear cell carcinoma [24]. Irregular nuclei, distinct nucleoli and nuclear pleomorphism are histological features of ChRCC. Referring to Fuhrman grade criteria, such as cell morphology, would indicate a higher stage of histological malignancy in this subtype of kidney cancer. However, long-term clinical observation of patients suffering from ChRCC refuted the prognosis that would result from the Fuhrman classification. In the vast majority of cases it was overstated.

These observations led scientists to create a new, three-level grade for chromophobe renal cell carcinoma. Evaluation of lesions according to this classification is based on the assessment of geographic nuclear crowding and cellular anaplasia.

Table I. Comparison of the Fuhrman and "the new grade" [23]

\begin{tabular}{|lcc|}
\hline $\begin{array}{l}\text { Stage of histological } \\
\text { malignancy }\end{array}$ & $\begin{array}{c}\text { Fuhrman } \\
\text { grade } \\
\text { (\% of ChRCC) }\end{array}$ & $\begin{array}{c}\text { “New grade” } \\
\text { (\% of ChRCC) }\end{array}$ \\
\hline 1 & 1 & 74 \\
\hline 2 & 19 & 16 \\
\hline 3 & 74 & 10 \\
\hline 4 & 6 & - \\
\hline
\end{tabular}

The 3 chromophobe tumor grades are as follows:

- grade 1 - chromophobe RCC with (usual) wide constitutive nuclear range, but without nuclear crowding and anaplasia (as defined in grades 2 and 3);

- grade 2 - geographic nuclear crowding (cellular clustering characterized by high geographic nuclear/cytoplasmic density detectable with the $10 \times$ objective and some nuclei in direct contact with each other when assessed with the 40x objective) and the presence of nuclear pleomorphism (size variation of $\geq 3$ ) - fold and distinct nuclear chromatin irregularities (unlike the smudged nuclear atypia of degenerate foci);

- grade 3 - presence of frank anaplasia (nuclear polylobation, tumor giant cells) or sarcomatoid change [25].

Paner et al. compared the Fuhrman grade ratings with the ratings based on the new classification (Table I).

In conclusion, the novel chromophobe tumor grading system proposed has a superior prognostic value compared to the Fuhrman nuclear grade in ChRCC and will potentially help stratify ChRCC patients who are at a potentially greater risk of disease progression [26].

Research shows that the assessment of grade of both systems does not correlate with age or gender. The correlation between grade and size of the tumor seems to be important. It was found that tumor size is in a linear relationship with the risk of relapse [26]. An increase grade in both scales was observed with increased angiogenesis and the formation of necrotic lesions [25, 27]. The new ChRCC evaluation system creates better possibilities for assessment of prognosis and the risk of progression of cancer. This allows better definition of groups of patients who should be under special care due to increased risk of relapse.

Eighty-six percent of ChRCC cases are diagnosed in the first and second clinical stage of the disease. Metastases are observed in a small number of cases (about 6-7\%), and involve mainly the liver (39\%) and lungs (36\%) [10, 28].

Microscopic evaluation of ChRCC can identify two types of cells. The first type includes cells that are large, polygonal with abundant clear cytoplasm and prominent cellular membranes. Typically, they are mixed with cells of the second type that are smaller, with granular, eosinophilic cytoplasm. Both types have irregular nuclei with a characteristic halo around them. Presence of cells with double nuclei is also possible [29, 30]. Cells of both types may be present in different proportions. This serves as the basis for the division into three ChRCC histological types, which 
Table II. Histological types of chromophobe renal cell carcinoma (ChRCC) [8, 30]

\begin{tabular}{|c|c|}
\hline Histological type of ChRCC & Morphological characteristic of cells \\
\hline Type I - eosinophilic & $\begin{array}{l}\text { Contains over } 80 \% \text { eosiniphilic cells; has areas with characteristics similar } \\
\text { in structure to oncocytoma }\end{array}$ \\
\hline Type II - mixed & $\begin{array}{c}\text { Has characteristics of both types; includes cells similar to type I, but larger, with } \\
\text { visible translucent perinuclear zone }\end{array}$ \\
\hline Type III - classic & $\begin{array}{c}\text { Contains over } 80 \% \text { pale cells and is associated with necrotic and sarcomatoid } \\
\text { changes; cells are separated from each other by distinct cell membranes; cells } \\
\text { contain abundant, clear cytoplasm }\end{array}$ \\
\hline
\end{tabular}

makes these tumors a heterogeneous group of lesions (Table II).

Chromophobe renal cell carcinoma may rarely occur in a sarcomatoid form. This type of lesion is characterized by spindle-shaped, closely packed cells, the presence of atypical cells and frequent occurrence of necrotic lesions and strong vascularization of the affected area. Changes of this type are often diagnosed at an advanced stage of the disease, often with metastases, and are characterized by a much worse prognosis. However, in contrast to other types of ChRCC, the sarcomatoid variant is more sensitive to chemotherapy [31].

\section{Diagnostic difficulties and molecular markers}

A benign lesion, such as oncocytoma, can often be confused with ChRCC because it is built from large, well-differentiated tumor cells with eosinophilic cytoplasm containing numerous granules. A microscopic granulation arises due to presence of numerous mitochondria in the cytoplasm of the oncocytoma [12, 32]. Moreover, both changes are characterized by the same origin [33]. Differentiation of ChRCC from clear cell carcinoma with eosinophilic cytoplasm can also be problematic. Therefore, it is necessary to identify molecular markers that will allow for a differential diagnosis of these changes.

Histopathologic diagnosis of ChRCC can be a diagnostic challenge because these tumors may resemble oncocytoma or conventional cancer. Research by Mathers et al. proposed the use of cytokeratin 7 as a marker useful in the differentiation of these changes. As a result of immunohistochemistry, the staining pattern of different types of changes has been determined:

- chromophobe renal cell carcinoma showed expression of cytokeratin 7 in the membranes of tumor cells,

- conventional cancer showed no expression of cytokeratin 7 ,

- oncocytoma showed heterogeneous expression of cytoplasmic staining with light to moderate areas.

Characteristic tint of ChRCC cell membranes was not observed [34].

In the diagnosis and treatment of ChRCC it is very important to distinguish potentially benign tumors with a higher risk of recurrence, despite the treatment used. Prognostic factors were studied by Zini et al. They thoroughly analyzed histological specimens and results of imaging of pathological changes in an attempt to find necrotic areas. Observation of patients after surgical removal of ChRCC (mean time of surgery was 22.5 months, range: $1-80$ months) revealed the presence of metastases in 19\% of patients, which clearly correlated with earlier detection of necrosis. Observation of cells surrounding the tumor necrosis is new, clinically useful information for the physician, which allows the aggressive form of ChRCC to be distinguished [35].

This method is simple and seems to be effective in estimating the prognosis of chromophobe renal cell carcinoma. In order to detect any local recurrence of the disease or distant metastases early, abdominal imaging should be carried out every 6 months. Particular attention should be paid to the liver, which is the most common site of metastasis in the course of ChRCC.

\section{Tumor markers in the immunohistochemical diagnosis of ChRCC}

\section{CD117}

CD117 (KIT) is also known as proto-oncogene c-Kit or tyrosine-protein kinase Kit. It is a protein encoded by the KIT gene. It was first described by the German biochemist Axel Ullrich in 1987. CD117 is a receptor tyrosine kinase type III, which is responsible for transduction of molecular signals. Under normal conditions, CD117 is activated (phosphorylated) by binding of the ligand - stem cell factor. This reaction activates an intracellular phosphorylation cascade leading to the formation of appropriate transcription factors, which activate the differentiation processes, apoptosis, proliferation, chemotaxis and cell adhesion.

KIT-dependent cells include mast cells, some hematopoietic cells, embryonic cells, melanocytes, interstitial cells of Cajal and cancer cells derived from these cells. Among them are also normal epithelial cells covering skin appendages and some clusters of neurons of the cerebellum. Overexpression of KIT has been described in the cells of various sarcomas, lung cancer and chromophobe 
renal cell carcinoma, lesions in the thymus gland and some changes involving the ovaries [36].

In healthy kidney tissue, poor immunoreactivity towards KIT is present in only some cells of the distal tubules. Interestingly, from among all types of kidney cancer, only ChRCC cells overexpress this receptor. This finding unequivocally confirms the histogenetic origin of this change and may be helpful in the differential diagnosis and treatment $[37,38]$. However, overexpression has slight variations depending on the subtype of ChRCC. It occurs more commonly in the classic (82\%) than the eosinophilic type (67\%) [39].

\section{Cadherins}

Taki et al. studied the expression of cadherins to propose a method of differentiating ChRCC from clear cell carcinoma, the most common type of kidney cancer. Cadherins belong to a group of adhesive proteins that require the presence of calcium ions for interaction between cells. It was found that in all cases of ChRCC, cancer cells expressed E-cadherin (epithelial) and there was a total lack of expression of $\mathrm{N}$-cadherin (neuronal). In the case of clear cell carcinoma, the proportion was opposite. This tumor displayed a total lack of E-cadherin; however, $58 \%$ of samples were positive for $\mathrm{N}$-cadherin [40].

\section{Genetic anomalies}

In order to differentiate ChRCC from oncocytoma, Qian et al. used fluorescence in situ hybridization (FISH) to identify specific genetic anomalies in the material. Frequent loss of chromosomes 2, 6 and 10 was a characteristic feature of ChRCC, whereas oncocytoma displayed very frequent loss of chromosomes 6 and 10, and no loss of chromosome 2 [41].

The effectiveness of using FISH probes specific for the detection of chromosome centromeres is not confirmed by larger studies. For this reason, it may not be used as a primary method, but only can play a supporting role in the diagnosis of ChRCC and oncocytoma.

\section{The S-100 protein family}

Also helpful in differentiating ChRCC and oncocytoma may be the results of Li et al., which suggest that the protein $\mathrm{S} 100 \mathrm{~A} 1$ belonging to the S100 protein family may be a useful diagnostic marker [42]. These proteins affect the activity of enzymes, transcription, and rearrangement of all cytoskeletal components. They can also be secreted out of the cell, where they are responsible for regulation of the body's calcium and signaling. S100A1 protein undergoes multiple conformational changes due to binding of calcium ions. Although still poorly understood, S100A1 protein function is suspected to take part in intracellular signaling and regulation of function of neurons and cardiomyocytes [42].

Li et al. reported that $93 \%$ of lesions previously diagnosed as oncocytoma showed S100A1 protein expression, while none of the ChRCC specimens showed a positive reaction. It was also noted that this method may only be useful in differentiating these two particular types of cancer. Differentiation of other types of renal cancer using this method is impossible because they exhibit variable expression of the protein (a positive response in $67 \%$ of clear cell carcinoma cases and also $67 \%$ for papillary cell carcinoma) [42].

\section{KAI1 protein}

KAI1 protein (CD82; metastasis suppressor protein) is a surface glycoprotein encoded by a KAl1 gene located on chromosome 11p11.2. This is a metastasis suppressor protein. Its expression is strongly correlated with the expression of p53 protein. Decreased expression of both of these proteins is associated with poor prognosis in the course of many cancers, as manifested by an increased number of tumor metastases and more aggressive clinical course [43].

Kauffman et al. evaluated protein expression level in various types of kidney cancer. Based on these results, the authors found expression of KAI1 in ChRCC and determined that it is much more frequent than in other histological types of renal cell carcinoma [44] (Tables III and IV).

\section{Systemic therapy for chromophobe renal cell carcinoma}

Research on chromophobe renal cell carcinoma is necessary to achieve the most effective therapy. Still target therapy for this cancer is not avail-

Table III. Immunohistochemical evaluation of KAI1 protein expression in different histological types of kidney cancer $[43,44]$

\begin{tabular}{|lcccc|}
\hline & \multicolumn{2}{c|}{ Histological types of kidney cancer } \\
\cline { 2 - 5 } & Clear cell carcinoma & $\begin{array}{c}\text { Papillary renal cell } \\
\text { carcinoma }\end{array}$ & Oncocytoma & $\begin{array}{c}\text { Chromophobe renal } \\
\text { cell carcinoma }\end{array}$ \\
\hline $\begin{array}{l}\text { Percentage of lesions } \\
\text { displaying KAl1 protein } \\
\text { expression [\%] }\end{array}$ & 6.3 & 3.0 & 3.4 & 87.5 \\
\hline
\end{tabular}


Table IV. Tumor markers, histochemical and immunohistochemical methods in the diagnosis of chromophobe renal cell carcinoma

\begin{tabular}{|c|c|c|c|c|}
\hline \multirow{2}{*}{$\begin{array}{l}\text { Tumor markers, histochemi- } \\
\text { cal and immunohistochemical } \\
\text { methods }\end{array}$} & \multicolumn{3}{|c|}{ Histological types of kidney cancer } & \multirow[t]{2}{*}{ References } \\
\hline & $\begin{array}{l}\text { Clear cell } \\
\text { carcinoma }\end{array}$ & Oncocytoma & $\begin{array}{l}\text { Chromophobe } \\
\text { renal cell carcinoma }\end{array}$ & \\
\hline Hale's colloidal iron & $+/-$ & + & + & {$[45]$} \\
\hline Keratin & + & + & + & [48] \\
\hline Vimentin & $+/-$ & $+/-$ & - & {$[46,47]$} \\
\hline CD117 (KIT) & - & - & $+/-$ & [37-39] \\
\hline E-cadherin & - & NDA & + & {$[40]$} \\
\hline $\mathrm{N}$-cadherin & $+/-$ & NDA & - & {$[40]$} \\
\hline Cytokeratin 7 & - & $+/-$ & + & {$[32]$} \\
\hline \multicolumn{5}{|l|}{ Loss of whole chromosomes: } \\
\hline 2 & NDA & - & $+/-$ & {$[41]$} \\
\hline 6 & NDA & - & $+/-$ & \\
\hline 10 & NDA & - & $+/-$ & \\
\hline S100A1 protein & $+/-$ & + & - & [42] \\
\hline KAl1 (CD82) & - & - & $+/-$ & {$[43,44]$} \\
\hline
\end{tabular}

"+" from 90 to $100 \%$ of lesions whose cells showed positive immunohistochemical reaction; "-" less than 10\% of lesions whose cells showed a positive reaction in immunohistochemistry, "+/-" from 10\% to 90\% of lesions whose cells showed a positive reaction in immunohistochemistry, NDA - no data available.

able. Although many specific molecules have been found as targets for the new medicaments, none can be used in the clinic. According to the Guidelines on Renal Cell Carcinoma [49] issued by the European Association of Urology in 2014, no recommendations can be made at present. There are limited data supporting the use of targeted therapy in chromophobe tumors. These lesions have been included in prospective studies, but the numbers are small, and specific subset analysis has not been performed [50-52]. Patients should be treated in the framework of clinical trials. If a trial is not available, a decision should be made in consultation with the patient to perform treatment in line with clear-cell carcinoma. Guidelines suggest using sunitinib, everolimus or temsirolimus as a first-line therapy. Sunitinib is an oral tyrosine kinase inhibitor [53]. Both everolimus and temsirolimus are specific inhibitors of mammalian target of rapamycin (mTOR) [54]. For the second-line treatment any targeted agent may be used.

\section{Conflict of interest}

The authors declare no conflict of interest.

\section{References}

1. Clague J, Lin J, Cassidy A, et al. Family history and risk of renal cell carcinoma: results from a case-control study and systematic meta-analysis. Cancer Epidemiol Biomarkers Prev 2009; 18: 801-7.

2. Chow WH, Dong LM, Davesa SS. Epidemiology and risk factors for kidney cancer. Nat Rev Urol 2010; 7: 245-57.

3. Fengqiang $Y$, Yang S, Fengping $Y$, et al. Valproic acid upregulates NKG2D ligand expression and enhances susceptibility of human renal carcinoma cells to NK cell-mediated cytotoxicity. Arch Med Sci 2013; 9: 32331.

4. Kruś S, Skrzypek-Fakhoury E. The surface morphology of kidney diseases. In: Clinical pathology. Kruś S, Skrzypek-Fakhoury E (eds). 3rd ed. Publisher Medical PZWL, Warsaw 2011; 545-606.

5. Cotran RS, Rennke H, Kumar V. Kidney and roads discharging urine. Tumors. In: Robbins pathology. Kumar V, Cotran RS, Robbins SL (eds). Elsever Urban \& Partner, Wroclaw 2009; 615-9.

6. Thoenes W, Störkel S, Rumpelt HJ. Human chromophobe cell renal carcinoma. Virchows Arch B Cell Pathol Incl Mol Pathol 1985; 48: 207-17.

7. Fromowitz FB, Bard RH. Clinical implications of pathologic subtypes in renal cell carcinoma. Semin Urol 1990; 8: 31-50.

8. Dijkhuizen T, van den Berg E, Störkel S, de Jong B. Chromosome changes in a metastasis of a chromophobe renal cell tumor. Cancer Genet Cytogenet 1998; 105: 86-9.

9. Stec R, Grala B, Mączewski M, Bodnar L, Szczylik C. Chromophobe renal cell cancer - review of the literature and potential methods of traeting metastatic disease. J Exp Clin Cancer Res 2009; 28: 134.

10. Zini L, Leroy $X$, Lemaitre L, et al. Tumor necrosis in chromophobe renal cell carcinoma: clinical data to distunguish aggressive variants. Eur J Surg Oncol 2008; 34: 687-91. 
11. Cheville JC, Lohse CM, Zincke H, Weaver AL, Blute ML. Comparisons of outcome and prognostic features among histologic subtypes of renal cell carcinoma. Am J Surg Pathol 2003; 27: 612-24.

12. Amin MB, Crotty TB, Tickoo SK, Farrow GM. Renal oncocytoma: a reappraisal of morphologic feaures with clinicopathologic findings in 80 cases. Am J Surg Pathol 1997; 21: 1-12.

13. Machoy P, Podolski J, Lubiński J. Chromophobe renal cell carcinoma. Pol Urol 1995; 48: 311-3.

14. Wu SL, Fishman IJ, Shannon RL. Chromophobe renal cell carcinoma with extensive calcification and ossification. Ann Diagn Pathol 2002; 6: 244-7.

15. Vera-Badillo FE, Conde E, Duran I. Chromophobe renal cell carcinoma: a review of an uncommon entity. Int J Urol 2012; 19: 894-900.

16. Amin MB, Paner GP, Alvarado-Cabrero I, et al. Chromophobe renal cell carcinoma: histomorphologic characteristics and evaluation of conventional pathologic prognostic parameters in 145 cases. Am J Surg Pathol 2008; 32: 1822-34.

17. Dobroński P, Pych K. Renal cell carcinoma derived from a further nephron tubules. Chromophobe renal cell carcinoma. In: Renal neoplasms and cysts. Borkowski A Czaplicki M (eds). Publisher Medical PZWL, Warsaw 2002; 82-4.

18. Zbar B, Alvord WG, Glenn G, et al. Risk of renal and colonic neoplasms and sponthaneus pneumothorax in the Birt-Hogg-Dubé syndrome. Cancer Epidemiol Biomarkers Prev 2002; 11: 393-400.

19. Zhao PJ, Chen XP, Li XS, et al. Chromophobe renal cell carcinoma: analysis of 53 cases. J Cancer Res Clin Ocol 2012; 138: 451-4

20. Huang WC, Elkin EB, Lavey AS, Jang TL, Russo P. Partial nephrectomy versus radical nephrectomy in patients with small renal tumors: is there a difference in mortality and cardiovascular outcomes. J Urol 2009; 181: 55-61; discussion 61-62.

21. Thompson RH, Boorjian SA, Lohse CM, et al. Radical nephrectomy for PT1a renal masses may be associated with decreased overall survival compared with partial nephrectomy. J Urol 2008; 179: 468-71.

22. Elbe JN, Sauter G, Epstein J, Sesterhenn IA (eds). World Health Organization Classification of Tumours. Pathology and Geneticsc of Tumours of the Urinary System and and Male Genital Organs. IARC Press, Lyon 2004; 10-43.

23. Fuhrman SA, Lasky LC, Limas C. Prognostic significance of morphologic parameters in renal cell carcinoma. Am J Surg Pathol 1982; 6: 655-63.

24. Rodriguez Faba O, Pardo P, Breda A, et al. Accuracy of conventional pathologic predictive factors in histological subtype chromophobe renal cell carcinoma. Urology 2011; 78 (Suppl. 3A): S235.

25. Paner GP, Amin MD, Alvarado-Cabrero I, et al. A novel tumour grading scheme for chromophobe renal cell carcinoma: prognostic utility and comparison with Fuhrman nuclear grade. Am J Surg Pathol 2010; 34: 1233-40.

26. Thong A, Ngo T, Weinzierl E, Leppert J, McKenney J, Chung B. Clinicopathologic features and outcomes of a chromophobe renal cell carcinoma series from a single institution. J Urol 2012; 187: e240.

27. Finley DS, Shuch B, Said JW, et al. The chromophobe tumor grading system is the preferred grading scheme for chromophobe renal cell carcinoma. J Urol 2011; 186: 2168-74.

28. Beck SDW, Manish I, Patel IM, et al. Effect of papillary and chromophobe cell type on disease-free survival af- ter nephrectomy for renal cell carcinoma. Ann Surg Oncol 2004; 11: 71-7.

29. Prasad SR, Humphrey PA, Catena JR, et al. Common and uncommon histologic subtypes of renal cell carcinoma: imaging spectrum with pathologic correlation. Radiographics 2006; 26: 1795-806; discussion 1806-10.

30. Akhtar M, Kardar H, Linjawi T, McClintock J, Ali MA Chromophobe cell carcinoma of the kidney. A clinicopathologic study of 21 cases. Am J Surg Pathol 1995; 19: 1245-56.

31. Shuch B, Bratslavsky G, Linehan WM, Srinivasan R. Sarcomatoid renal cell carcinoma: a comprehensive review of the biology and current treatment strategies. Oncologist 2012; 17: 46-54.

32. Van der Kwast T, Perez-Ordoñez B. Renal oncocytoma, yet another tumour that does not fit in the dualistic benign/malignant paradigm? J Clin Pathol 2007; 60: 585-6.

33. Koeman JM, Russell RC, Tan MH, et al. Somatic pairing of chromosome 19 in renal oncocytoma assiociated with deregulated EGLN2-mediated [corrected] oxygen-sensing response. PLoS Genet 2008; 4: e1000176.

34. Mathers ME, Pollock AM, Marsh C, O'Donnell M. Cytokeratin 7: a useful adjunct in the diagnosis of chromophobe renal cell carcinoma. Histopathology 2002; 40: 563-7.

35. Zini L, Leroy X, Aubert S, et al. Aggressive variants of chromophobe renal cell carcinoma: a clinico-pathological study of prognostic factors. Urology 2007; 70: 128-9.

36. Miettinem M, Lasota J. KIT (CD117): a review on expression in normal and neoplastic tissues, and mutations and their clinicopathologic correlation. Appl Immunohistochem Mol Morphol 2005; 13: 205-20.

37. Yamazaki K, Sakamoto M, Ohta T, Kanai Y, Ohki M, Hirohashi S. Overexpression of KIT in chromophobe renal cell carcinoma. Oncogene 2003; 22: 847-52.

38. Lin ZH, Han EM, Lee ES, et al. A distinct expression pattern and point mutation of c-kit in papillary renal cell carcinomas. Mod Pathol 2004; 17: 611-6.

39. Krüger S, Sotlar K, Kausch I, Horny HP. Expression of KIT (CD117) in renal cell carcinoma and renal oncocytoma. Oncology 2005; 68: 269-75.

40. Taki A, Nakatani Y, Misugi K, Yao M, Nagashima Y. Chromophobe renal cell carcinoma: an immunohistochemical study of 21 Japanese cases. Mod Pathol 1999; 12: 310-7.

41. Qian J, Weber D, Hossain D, Liu L, Bostwick DG, Allen G. Detection of chromosomal anomalies in chromophobe renal cell carcinoma using fluorescence in situ hybridization. J Urol 2009; 181 (Suppl.): 245.

42. Li G, Barthelemy A, Feng G, et al. S100A1: a powerful marker to differentiate chromophobe renal cell carcinoma form renal oncocytoma. Histopathology 2007; 50: 642-7.

43. Binghui Z, Wei L, Liang L, et al. KAI1/CD82 and MRP1/ CD9 serve as markers of infiltration, metastasis, and prognosis in laryngeal squamous cell carcinimas. Asian Pac J Cancer Prev 2013; 14: 3521-6.

44. Kauffman EC, Barocas D, Yang XJ, Liu H, Scherr DS, Tu JJ. KAI1 is a novel biomarker for chromophobe renal cell carcinoma. J Urol 2008; 4 Suppl.: 134.

45. Tickoo SK, Amin MB, Zarbo RJ. Coloidal iron staining in renal epithelial neoplasms, including chromophobe renal cell carcinoma: emphasis on technique and patterns of staining. Am J Surg Pathol 1998; 22: 419-24.

46. Williams AA, Higgins JPT, Zhao H, Ljungberg B, Brooks JD. Cd 9 and vimentin distinguish clear cell from chromophobe renal cell carcinoma. Clin Pathol 2009; 9: 9. 
47. Hes $\mathrm{O}$, Michal M, Kuroda $\mathrm{N}$, et al. Vimentin reactivity in renal oncocytoma: immunohistochemical study of 234 cases. Arch Pathol Lab Med 2007; 131: 1782-8.

48. Langner C, Wegscheider BJ, Ratschek M, Schips L, Zigeuner R. Keratin immunohistochemistry in renal cell carcinoma subtypes and renal oncocytomas: a systematic analysis of 233 tumors. Virchows Archiv 2004; 444: 127-34.

49. Ljungber B, Bensalah K, Bex A, et al. Guidelines on renal cell carcinoma. 2014 Edition. European Association of Urology 2004.

50. Hudes G, Carducci M, Tomczak P, et al. Global ARCC Trial. Temsirolimus, intereferon alpha, or both for advanced renal-cell carcinoma. N Engl J Med 2007; 356: 2271-81.

51. Gore ME, Szczylik C, Porta C, et al. Safety and efficacy of sunitinib for metastatic renal-cell carcinoma: an expanded-access trial. Lancet Oncol 2009; 10: 757-63.

52. Motzer RJ, Michaelson MD, Redman BG, et al. Activity of SU11248, a multitargeted inhibitor of vascular endothelial growth factor receptor and platelet-derived growth factor receptor, in patients with metastatic renal cell carcinoma. J Clin Oncol 2006; 24: 16-24.

53. Larkin JM, Eisen T. Kinase inhibitors in the treatment of renal cell carcinoma. Crit Rev Oncol Hematol 2006; 60: 2016-26.

54. Motzer RJ, Escudier B, Oudard S, et al. RECORD-1 Study Group. Efficacy of everolimus in advanced renal cell carcinoma: a double-blind, randomised, placebo controlled phase III trial. Lancet 2008; 372: 449-56. 